\title{
Jérémie fut-il prophète pour les nations?
}

Von Ch. Bruston in Montauban.

M. Stade me paraît avoir raison de soutenir, contre le texte masorétique du livre de Jérémie, que Jérémie ne saurait avoir été établi "prophète pour les nations (לגוo I, 5)", ni institué sur les nations et sur les royaumes, pour démolir et pour renverserw etc. (v. IO).I C'est avant tout pour le peuple d'Israel que les prophètes, tous les prophètes, étaient institués, et de ce que tel ou tel d'entre eux a quelquefois prononcé aussi des oracles contre les peuples étrangers, il n'en résulte nullement qu'un tel prophète, Amos, Esaïe, Nahoum, Sophonie etc. - eût été établi pour les nations ou sur les nations, comme cela est dit, ou du moins semble dit de Jérémie dans ces deux textes. Je suis obligé de donner raison à $M$. Stade sur ce point.

Mais quand il en conclut $I^{\circ}$ que le verset 5 portait primitivement "ל et signifiait: "Je t'ai établi prophète pour ma nation", (et non pour les nations), $2^{\circ}$ que le v. Io tout entier est une addition postérieure, - je demande à réfléchir. Ces deux conclusions ne sont peut-être pas aussi nécessaires que le pense le savant et ingénieux critique.

I. Remarquons d'abord que le v. 8: "N'aie point peur d'eux" exige dans ce qui précède un substantif pluriel; auquel ce pronom pluriel puisse se rapporter. On dira probablement qu'il peut bien s'expliquer par l'antécédent supposé ma nation (collectif) ou par "contre quiconque je t'enverrai tu iras" (v. 7). Mais cela me parait fort douteux. "N'aie point peur (des gens) de ma

× Zeitschrift für die A. T. Wissenschaft 1906, p. 97. 
nation" serait une locution bien surprenante. "N'aie point peur de ceux contre qui je t'enverrain serait un peu plus tolérable, mais il serait pourtant plus naturel, plus régulier, qu'il y eût, avant, un substantif pluriel signifiant à peu près la même chose.

J'en conclus que le pluriel de לגוים est nécessaire, que ces גוים sont identiques aux personnages contre lesquels (ou vers lesquels) Dieu veut envoyer Jérémie et que par conséquent ce substantif pluriel doit avoir le même sens que גאים (Prov. XV, 25, XIV, 19. Ps. XCIV, 2. Es. II, I 2 etc). Je propose de traduire: "Je t'ai établi prophète pour les grandsn. ${ }^{x}$

On comprend alors beaucoup mieux pourquoi Jérémie, déclinant la mission qui lui est imposée, allègue qu'il ne sait pas parler. Pour se présenter devant les grands, en effet, il faut être sûr de soi et de sa parole. Une telle raison, s'il s'agissait de prophétiser sur les nations étrangères, serait assez étonnante. Pour une mission de cette nature il eût suffi de savoir écrire!

Remarquons aussi que Jérémie fut, en effet, habituellement en relation avec les grands, les prêtres, les rois de son peuple, de sorte que le titre de "prophète pour les grands" lui convient singulièrement mieux que celui de "prophète pour les nations".

2. On dira sans doute que cette explication est impossible parce qu'au v. Io, הגוים est suivi de הממלכות: "sur les nations et sur les royaumes", ce qui va fort bien ensemble, tandis que "sur les grands et sur les royaumes" est un rapprochement beaucoup moins naturel.

J'en conviens. Cependant réfléchissons encore: est-ce que réellement Jérémie ou un prophète quelconque a pu être "établi sur les nations et sur les royaumes pour les démolir, les arracher, les détruire; etc.? Jérémie, un prophète quelconque a-t-il jamais rien fait de pareil? Certainement non. Ils s'adressaient à leurs compatriotes, surtout aux puissants, aux infidèles etc.; mais comment auraient-ils fait pour renverser les nations et les royaumes

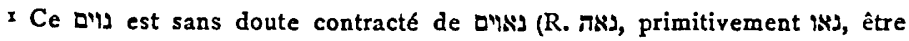
grand) comme II Elituation (XIII, 17. Job XII, 29 etc.) = Il faudrait donc prononcer ghteim. 
environnants? Ce sont les grands, les superbes de leur peuple qu'ils devaient abaisser et détruire par leur parole (cf. Is. II, I2, IV, I 5 etc.), s'ils ne parvenaient pas à les convertir. De sorte que la lecture על על הג(*)וים conviendrait encore fort bien ici.

Oui, mais les royaumes?

Remarquons, que ce mot הממלכr est suivi une fois d'un participe masculin (I Sam. X, I8), c-à-d. qu'il pouvait désigner des individus, des princes, et non des royaumes.

Et c'est précisément ce qu'il nous faudrait, à côté des grands.

On n'en trouve que cet exemple dans l'A. T.; mais en phénicien le même mot se rencontre au singulier, et là aussi (épitaphe d'Eshmoun-azar) il est accompagné d'un adjectif masculin: ממלך אדר ,un tyran superbe, un homme qui domine sur eux pour les détruire".x

Le v. Io pouvait donc signifier primitivement: "Je t'ai établi aujourd'hui sur les.grands et sur les tyrans, pour démolir, pour arracher, pour détruire, et pour renverser, pour construire et pour planter".

Et il n'y a plus alors aucune raison de douter de l'authenticité de ce verset.

3. Le texte parallèle XXXI, 27, confirme cette interprétation, car ceux sur qui Dieu dit, en cet endroit, qu'il a veillé (cf. I,-12) pour les démolir, arracher, détruire etc., c'est la maison d'Israel et la maison de Juda, et nullement les peuples étrangers. Et de même il promet de veiller sur eux (dans l'avenir) pour construire et pour planter.

Ces deux passages se confirment et s'expliquent l'un l'autre ${ }^{2}$;

I V. mes Etudes pheniciennes, p. 21.

2 M. Cornill juge au contraire que les versets 27 et 28 cadrent trop bien(!) arec l'organisme des chap. 30 et $3 \mathbf{I}$. Voilà une objection assez surprenante et qu'il est facile de transformer en argument. Il faut citer textuellement: „Es läbt sich nicht verkennen daß ... es mindestens stutzig machen muß, wie vortrefflich die Verse gerade in dem Organismus von Cap. 30 und 31 als Ganzes passen" etc.

S'ils ne convenaient pas dans cet organisme, faudrait-il donc en conclure leur authenticité?.. 
il serait bien étrange que le premier dît des peuples étrangers ce que l'autre ne dit que des maisons d'Israel et de Juda.

Remarquons aussi que, dans le second de ces textes, les verbes démolir, arracher etc. ont Dieu pour sujet. Il doit donc en être de même dans le premier. Le sujet des six verbes qui suivent doit être emprunté au verbe j'ai institué, et non au suffixe, Dieu a fait cela (établi Jérémie) pour démolir etc. c.-à.-d. pour que les paroles qu'il a mises ou mettra dans sa bouche (v. 9) aient pour effet de démolir etc. mais aussi de reconstruire et de planter, c.-à.-d qu'elles soient des malédictions et des menaces, ou au contraire des consolations et des promesses de relèvement. Juillet 1906. 